\title{
Application of Electrical Resistivity and DRASTIC Models in the Study of Groundwater Contamination Risk in the Surroundings of the Hulene - B Waste Dump, Maputo, Mozambique
}

\section{Bernardino Bernardo}

Universidade Pedagogica

\section{Carla Candeias}

Universidade de Aveiro

Fernando Tavares Rocha ( $\nabla$ tavares.rocha@ua.pt )

University of Aveiro https://orcid.org/0000-0002-3636-3933

\section{Research Article}

Keywords: Resistivity,Anomalous zones, DRASTIC, Risk of groundwater contamination.

Posted Date: February 1st, 2022

DOI: https://doi.org/10.21203/rs.3.rs-1257908/v1

License: (c) (1) This work is licensed under a Creative Commons Attribution 4.0 International License.

Read Full License 


\section{Abstract}

The contamination of groundwater by leachate migration around waste dumps is a growing challenge for maintaining the quality of water resources in urban centers. In this study the electrical resistivity method was applied, where six $400 \mathrm{~m}$ profiles were executed around the Hulene - B waste dump and then an inversion was performed by RES2D. The application of the electrical resistivity method allowed us to characterize in detail some of the fundamental aspects of the DRASTIC risk (estimating groundwater depth, characterizing the vadose zone and understand soil permeability) and to identify anomalous zones of possible fundamental contamination, which we grouped into two (i) anomalous lithological surfaces that we considered permeable and migrating leachate from the waste dump and (ii) anomalous zones in the subsoil and groundwater possibly contaminated. The computed DRASTIC index is very high for the area covered by profiles 2 and $6(156-165)$ given the proximity of groundwater to the contaminating surface and the surrounding area consisting of very conductive materials. On profile 5 area the index is very low (96) due to the strong resistivity of the surface layers and the high depth at which groundwater was detected $(>40 \mathrm{~m})$. The area of profile 3 (further north of the dump) has also a low index (105) due to its distance from the contamination source (dump) and the strong resistivity of the lithological layers, indicating low permeability, in addition to the great depth $(>40 \mathrm{~m})$ at which groundwater were detected. Concerning profiles 1 and 4, despite presenting permeable materials at the surface (low resistivities), groundwater level was recognized at greater depth $(>40 \mathrm{~m})$, DRASTIC risk index was lower $(115$ - 125) than expected. The overall value of the DRASTIC index for the surrounding area of Hulene - B dump was estimated at 127, which represents a low overall vulnerability. However, the high vulnerability index values for the area covered by profiles 2 and 6 , and given their relatively higher surficial altitude, suggest a strong groundwater contamination by horizontal dilution of leachates from the whole area surrounding of the Hulene - B waste dump.

\section{Introduction}

Urban areas are characterized by an excessive production of solid waste (González-Arqueros et al. 2021) which can often be deposited in areas not prepared for disposal or treatment, thus posing a risk of environmental contamination (Rathi et al. 2021), especially of soils and groundwater, which are described in many studies as extremely vulnerable (Boufekane et al. 2021). The concept of groundwater vulnerability first evolved in the early 1960s, with the aim of identifying areas prone to contamination (Saranya and Saravanan 2021). Groundwater vulnerability results not only from the properties of the groundwater flow system, but also from the proximity of contaminant sources, the character of the contaminant and other factors that can cause potential contaminants to reach groundwater resources as quickly as possible (Sresto et al. 2021). In urban areas, one of the main sources of groundwater contamination is leachate resulting from the decomposition of solid urban waste when deposited without treatment in unplanned locations such as waste dumps (Ghosh et al. 2021). Several non-invasive models have been developed to assess groundwater vulnerability in urban areas, of which geophysics in 
particular electrical resistivity and the DRASTIC hydrogeological model are pointed out as the most relevant (El Mouine et al. 2021).

The electrical resistivity method has been prominent in locating buried hazardous waste as well as in identifying different sources of contamination in the subsurface environment (Kayode et al. 2019; Oum et al. 2021), being widely used in identifying areas of heavy metal contamination, contamination plumes (Liu et al. 2021), groundwater (Oum et al. 2021) and lithological variations (Kayode et al., 2019; Mepaiyeda et al. 2020). DRASTIC model was established by Aller (1987) with the American Environmental Model Protection Agency and the National Water Well Association. Seven hydrogeological parameters are included in the DRASTIC model (Aller 1987). These parameters constitute acronyms that form the term "DRASTIC" and include depth to water table, net area recharge, aquifer media, soil media, topography, the impact of the vadose zone, and hydraulic conductivity (Aller, 1987). Conventionally, DRASTIC has been applied to map relatively large areas of groundwater vulnerability in urban areas ( $>40$ ha), according to Gemail et al. (2017) and Voudouris (2021). Shah et al. (2021), Arowoogun et al. (2021), Dhakate et al. (2021) and George (2021) shown it to be most effective when applied locally and combined with the electrical resistivity method to study the contamination plumes migration from different sources (Dumps, mines, cemeteries) and estimate groundwater vulnerability.

Nogueira et al. (2019) and Cendón et al. (2020) have described groundwater in Maputo City as vulnerable to contamination due to its hydrogeological context characterized by the proximity (to surface) of the groundwater level and the rapid expansion of the city without adequate planning and structured sanitation system. Recently, Bernardo et al. (2021), described that in the surroundings of the Hulene - B dump there is a strong risk of leachate migration through the adjacent lithologies and, consequently, the possible contamination of groundwater. This study aims to apply the electrical resistivity method and the DRASTIC model to estimate the risk of groundwater contamination by leachate in the area surrounding of the Hulene B waste dump, Maputo, Mozambique.

\section{Materials And Methods}

\subsection{Study area}

The Hulene B waste dump is considered one of the largest in the country (Serra 2012), being located in Maputo city, the capital of Mozambique (Fig. 1a), on a residential area, the Hulene - B neighborhood, with approximately 27.996 inhabitants (Bernardo et al. 2022). The immediate around of the dump was densely populated until February 2018, and the fall of a large mass of waste caused the collapse of 32 houses and the death of 18 inhabitants, which led to the forced removal of the population within a radius of $50 \mathrm{~m}$ of the dump (VOA 2018; Serra 2012). The dump receives all types of waste produced in Maputo City (Serra 2012; Sarmento et al. 2015). The height of the waste is estimated to be about $6 \mathrm{~m}$ to $15 \mathrm{~m}$ and occupies an area of $\sim 17$ hectares (Palalane 2008). The waste dump is in a former quarry with no previous preparation for waste reception (Ferrão 2006; Bernardo et al. 2022). 
The Hulene B waste dump is inserted in the Mesocenozoic sedimentary basin of southern Mozambique (Afonso 1978) and is situated in a contact zone of two lithologies (Ponta Vermelha Formation and Malhazine), on a gentle dune slope with east-west orientation (Momade et al. 1996) (Fig. 1b). The Ponta Vermelha Formation (TPV) dates from the upper Pliocene to the lower Pleistocene, being composed in the upper part of ferruginous sandstones and red silty sands, which gradually change to yellow and whitish sands (Momade et al. 1996); at the surface this unit presents a red color, being poorly consolidated, and loose sands may appear (Cendón et al. 2020). The Malhazine Formation (QMa), from upper Pleistocene, consists of fine, poorly consolidated sands with whitish to reddish colors, fixed by vegetation because of successive consolidation processes (Momade et al. 1996).

The Hulene-B hydrogeological system is part of the Tertiary - Quaternary aquifer system (Cendón et al. 2020). The aquifer substrate is formed by a layer of clayey marl to grey clay (Cendón et al. 2020; Muchimbane 2010). In the surroundings of the Hulene-B dump the localized presence of the semiimpermeable layer (clayey sands), between the fine to coarse sand and the sandstones, causes the water circulation of these two sectors to continuously connect (Muchimbane 2010). There are places where the coarse sands lie directly on top of the clay layer, developing semi-confined conditions (Nogueira et al. 2019). The water level of the shallow wells varies between 1.5 and $9.3 \mathrm{~m}$ deep, with an average of $3.8 \mathrm{~m}$ (Cendón et al. 2020). Bernardo et al. (2021) used sections of electrical resistivity profiles between 2020 2021 and demonstrated that groundwater at the western boundary of the Hulene - B dump was at variable depths and at potential risk of being contaminated by leachate plumes resulting from vertical and horizontal migration, which, in the subsurface environment, were assigned $d$ values from $<4.26$ to < $8.5 \Omega . m$. The hydraulic conductivity was estimated at $1-5 \mathrm{~m} / \mathrm{d}$ (Muchimbane, 2010).

The predominant climate is of subtropical type, with two seasons: (a) hot and rainy period from December to March with more than $60 \%$ of the annual precipitation, with the highest concentration of precipitation in January (average $125 \mathrm{~mm}$ ) and (b) dry and cold season from April to September with lower temperatures in June and July, as well as a weak and irregular precipitation, whose minimum values are recorded in August $12 \mathrm{~mm}$. The average annual precipitation is 789,2 mm (INAM 2020). The prevailing winds are SE (Muchangos 1999).

\subsection{Geophysical Studies (Electrical Resistivity)}

The resistivity method is based on the electric current injected into the ground through a pair of electrodes ( $A$ and $B$ - current electrodes) and the resulting potential difference between another pair of electrodes ( $M$ and $\mathrm{N}$ - potential electrodes) (Koda et al. 2017). The ground resistivity is calculated from the distances between the electrodes, applied current and measured potential difference, based on the Law of Ohm (Lau et al. 2019).

The electrical resistivity of soils is a characteristic closely linked to the type, nature, and state of alteration of geological formations (Kayode et al. 2019). In areas of suspected groundwater contamination, the method has been employed for: (1) determining the depth of the groundwater table (Akhtar et al. 2021), 
(2) determining the distribution of contamination zones and the direction of migration of pollutants; and (3) assessing the thickness of waste deposited in a landfill and (4) identifying possible leachate plumes (Koda et al. 2017; Adamo et al. 2020; Bernardo et al. 2022). In this investigation 6 electrical resistivity profiles were performed in May 2021, of which 4 were at the western edge of the dump and two profiles on the southern and northern borders respectively (Fig. 1a). Profile 3, north of the dumpsite, was applied to understand the possible migration of contaminants away from the dumpsite. ABEM SAS 4000 was used for the data acquisition resistor, including 4 rollers of $100 \mathrm{~m}$ cables with 21 outlets that connect to the same number of electrodes. The layout produced by this sequence of cables (100 m and 21 outputs) corresponds to the standard of the reading program hosted by the resistivimeter LUND Imaging System. Data acquisition employed a $50 \mathrm{~Hz}$ current frequency, using a multigradient protocol (GRAD4LX8 and GRAD4SX8), the GRAD4LX8 was selected because it provides dense coverage the nearby surface and adopts the Wenner-Schlumberger protocol (ABEM 2018). The electrode spacing for data acquisition was $5 \mathrm{~m}$. All the electrodes take-outs were connected in the GRAD4S8 protocol. The resistivimeter automatically switches the electrodes to serve as current or potential pairs. After the readings, the data was transferred to the resistivimeter, which then takes the readings, 3 minimum and 6 maximums, to obtain the smallest error average between readings. The inversion of the electrical resistivity data obtained in the 6 lines was done based on the standards defined in the software RES2DINV3.59.106, namely: application of the smoothness constraint method in the resistivity values of the final model, calculation of the Jacobian matrix in each iteration, standard Gauss-Newton optimization method (Geotomo 2010). The interpretation of the profiles was based on the direction of each profile over the entire length $(400 \mathrm{~m})$

\subsection{Groundwater pollution risk index (DRASTIC)}

The risk index of groundwater contamination in the surrounding of the Hulene B waste dump has been determined based on the DRASTIC model. This model has been commonly used in studies of areas where geographical, hydrogeological information is available and has been successfully applied in different regions (Anshumala et al. 2021; Shah et al. 2021). The model has been applied to determine the groundwater vulnerability index of the watershed (Aller 1987). The word DRASTIC is an abbreviation of initial letter of different parameters such as ' $D$ ' to depth to water; ' $R$ ' to net recharge, ' $A$ ' to aquifer media, ' $S$ ' to soil media, ' $T$ ' to topography, ' $I$ ' the impact of the vadose zone media, and ' $C$ ' to the hydraulic conductivity of the aquifer Intrinsic vulnerability (IV) of groundwater is evaluated by the DRASTIC modelling terms of the DRASTIC Index formula which is given below:

DRASTIC Index (IV) $=D_{r} D_{w}+R_{r} R_{w}+A_{r} A_{w}+S_{r} S_{w}+T_{r} T_{w}+I_{r} I_{w}+C_{r} C_{w}$ Eq. (1)

where " $r$ " is the rating value, and " $w$ " is the weight assigned to each parameter. Each factor is assigned a relative weight ranging from 1 to 5 (Table 1). Each DRASTIC factor is divided into ranges that affect the contaminant potential. The range for each factor lies from 1-10 (Table 1). The DRASTIC model depends on seven boundaries or layers, which are utilized as input boundaries for modeling (Table 1). Thus, the interpretation of the index follows three categories: (i) indices below 135 denote a low vulnerability of the area; (ii) indices between 135 and 150 represent medium vulnerability and (iii) indices above 150 indicate 
a high vulnerability of the site to groundwater-related environmental impacts (Aller 1987 and Ghosh et al. 2021). A recent systematization study on the application of the DRASTIC model to groundwater vulnerability assessment made by Voudouris (2021) showed that many studies applied the DRASTIC method for larger areas $>40$ ha and combined it with ArcGIS (Persaud \& Levison, 2021). However, recently Shah et al. (2021) applied DRASTIC and electrical conductivity to assess groundwater vulnerability in a small area in Safdar Abad Tehsil, Pakistan and demonstrated the role of lithologies of different resistivity in controlling contamination. In this study, the analysis covers an area of about $\sim 32$ ha.

The DRASTIC model results for each area covered by the electrical resistivity profile resulted from the combination of local hydrogeological information and interpretation of the resistivity models. For groundwater depth, we combined the data from Cendón et al. (2020) and Muchimbane (2010) which estimated groundwater depth in the study area between 1.5 and $9.3 \mathrm{~m}$ and were compatible with the model resistivity data for profiles 2 and 6 a weight of (9) was assigned and for the areas covered by profiles 3,4 and 5 a depth $>40 \mathrm{~m}$ estimated according to the model resistivity data, weight (1). For the aquifer recharge network, we used the data from Momade et al. (1996) which estimates the average aquifer recharge for the Maputo region to be $165-185 \mathrm{~mm} /$ year. Thus, a value of 8 was assigned to the entire area surrounding the dump. The lithological substratum of the aquifer was classified as sandstone according to Momade et al. (1996) and assigned a weight of 9 for all areas. The vadose zone for the area covered by profiles 2, 4 and 6 received a classification of 9 because it is composed of sandy layers in all four profiles, which are proportional to the low electrical resistivity data of the upper layers of the profiles, in addition to the water table being at low depth (Cendón et al. 2020). Thus, for the area covered by profiles 3 and 5 a value of 4 was assigned, corresponding to sandstones, given the strong compaction of the upper layers and the high depth of the water table in both areas, well evidenced by the high resistivity in the upper layers of profiles 3 and 5. The area covered with the profile 1, given the heterogeneity of the resistivities of the surface layers, a weight of 6 . The hydraulic conductivity was assigned a value of 2 and was assigned based on (Muchimbane 2010) data which estimates the hydraulic conductivity of the Hulene - B waste district at 1-5 m/day. Shah et al. (2021) and George (2021) demonstrated that groundwater vulnerability analysis using a combination of electrical resistivity and DRASTIC has successfully achieved good results and reduces generalizability in risk assessment. 
Table 1

The weight assigned to DRASTIC parameters

Factor Interval/Characteristics

$\begin{array}{llll}\text { (D) } & 0-1.5 & 10 & 5\end{array}$

$\begin{array}{llll}\text { (D) } & 0-1.5 & 10 & \mathbf{5}\end{array}$

Value

(r)

Weight

(w)

$\begin{array}{lll}\text { Groundwater depth }(\mathrm{m}) & 1.5-4.6 & 9\end{array}$

$\begin{array}{ll}4.6-9.3 & 7\end{array}$

$9.3-15 \quad 5$

$15-23$

$23-30 \quad 2$

$>30$

1

(R)

$0-50$

1

4

Net Recharge (mm/day)

$50-100$

3

$100-175$

6

$175-250$

8

$>250$

9

(A)

Massive Slate

$1-3$

3

Lithology

Igneous and metamorphic rocks

$2-5$

Altered igneous and metamorphic rocks

$3-5$

Thinly bedded successions of sandstones,

$5-9$

limestones, and shales

Massive sandstones

$4-9$

Massive limestones

$4-9$

Sand and gravel

$6-9$

Basalts

$2-$

10

Limestones and Karstics

$9-$

10

(S)

Non-expansive clay

1

Soil Type

Clay-French

3

1

Sandy siltstone

4

Franco

5 


\begin{tabular}{|c|c|c|c|}
\hline Factor & Interval/Characteristics & $\begin{array}{l}\text { Value } \\
(r)\end{array}$ & $\begin{array}{l}\text { Weight } \\
\text { (w) }\end{array}$ \\
\hline & Sandy frank & 6 & \\
\hline & Expansive clay & 7 & \\
\hline & Sandy soil & 9 & \\
\hline & Soil with gravel & 10 & \\
\hline & Thin soil & 10 & \\
\hline \multirow{5}{*}{$\begin{array}{l}(\mathrm{T}) \\
\text { Terrain slope (\%) }\end{array}$} & $0-2$ & 10 & \multirow[t]{5}{*}{1} \\
\hline & $2-6$ & 9 & \\
\hline & $6-12$ & 5 & \\
\hline & $12-18$ & 3 & \\
\hline & $>18$ & 1 & \\
\hline \multirow{10}{*}{$\begin{array}{l}\text { (I) } \\
\text { Vadose Zone }\end{array}$} & Clays and silts & $1-2$ & \multirow[t]{10}{*}{5} \\
\hline & Shales & $2-5$ & \\
\hline & Limestones & $2-7$ & \\
\hline & Sandstones & $4-8$ & \\
\hline & Limestones, sandstones and shales & $4-8$ & \\
\hline & $\begin{array}{l}\text { Sands and gravels with significant silt and clay } \\
\text { content }\end{array}$ & $4-8$ & \\
\hline & Igneous and metamorphic rocks & $2-8$ & \\
\hline & Sand and gravel & $6-9$ & \\
\hline & Basalts & $\begin{array}{l}2- \\
10\end{array}$ & \\
\hline & Karst limestones & $\begin{array}{l}8- \\
10\end{array}$ & \\
\hline (C) & $1-4.1$ & 1 & \multirow[t]{6}{*}{4} \\
\hline \multirow{5}{*}{$\begin{array}{l}\text { Hydraulic conductivity } \\
\text { (m/day) }\end{array}$} & $4.1-12.2$ & 2 & \\
\hline & $12.2-28.5$ & 4 & \\
\hline & $28.5-40.7$ & 6 & \\
\hline & $40.7-81.5$ & 8 & \\
\hline & $>81.5$ & 10 & \\
\hline
\end{tabular}




\section{Results}

\subsection{Resistivity models and contamination risks}

The resistivity models were analyzed to identify the possible influence of the dumpsite on groundwater contamination, thus we identified two anomalous zones reflecting the leachate transfer process: (i) contaminated lithologies that we consider as leachate migration sites to the groundwater media (ii) groundwater and surface water contaminated by leachate. For all profiles, the areas considered anomalous have been highlighted (dashed).

\section{Profile 1}

Profile 1, which extends from south to north of the dump (Fig. 2), is superficially characterized by high resistivity associated with rubble, house debris and compacted waste in non-wet environments from 0 to $35 \mathrm{~m}$. From 240 to $400 \mathrm{~m}$ there are zones of rather heterogeneous anomalous resistivity, which we consider as zone of influence of the possible leachates (< $15.0-10.7 \Omega . \mathrm{m})$ from the dump and moving E$W$ (profile 2) and diluting with the surface waters causing their possible contamination ( $<8.56-6.85$ $\Omega . \mathrm{m})$. At deeper levels between 30 and $56.5 \mathrm{~m}$, anomalous zones are observed, which we consider as lithologies influenced by leachate $(15-10.7 \Omega . \mathrm{m})$ and possible contaminated groundwater $(>45 \mathrm{~m}$ depth) by vertical migration of leachate $(<8.56-6.85 \Omega . m)$.

\section{Profile 2}

Profile 2, along W-E direction (Fig. 3), is quite heterogeneous, with high surface resistivities from $0-140$ $\mathrm{m}$, which represent for rubble, old house debris, waste buried in non-wet environment west of the dump, followed, from $140 \mathrm{~m}$ to $160 \mathrm{~m}$, by a zone of possible migration of surface leachate into the subsurface environment, causing an extensive zone of subsurface anomalies, which we consider as lithologies contaminated by strong horizontal migration of leachate in the E-W direction (16.8 - $7.99 \Omega . \mathrm{m}$ ) and satured zone and contaminated groundwater ( $<7.99$ - $4.96 \Omega . \mathrm{m}$ ) differentiated levels of semiconfinement of aquifers. From $245 \mathrm{~m}$ to $400 \mathrm{~m}$ of surface there are local anomalies and lithologies with high resistivities, corresponding to highly compacted waste with diverse moisture contents. At depths ranging from 30 to $160 \mathrm{~m}$, semi-confined anomalies (< $8.35 \mathrm{~m}$ depth) and aquifers (> $10 \mathrm{~m}$ depth) separated by semi-saturated layers are noted, demonstrating the existence of a possible continuous connection between the two. These characteristics are described as conducive for groundwater contamination at various depths, mainly in the surroundings of the Hulene B dump, where surface leachate flows are noted that successively enrich the lithological layers $(<16.8-7.99 \Omega . m)$.

\section{Profile 3}

Profile 3 (Fig. 4) runs north of the dump in S-N direction to study the possible dynamics of groundwater contamination about $300 \mathrm{~m}$ away from the dump. The profile at surface level exhibits generally high resistivities, which alternate between rubble and highly compacted soils. At the deeper level $(>40 \mathrm{~m})$ in 
the southern end we note anomalous zones that we consider as contaminated lithologies $(<15.95$ - 9.95 $\Omega . m)$ and satured zone and contaminated groundwater (< $9.99-<7.43 \Omega . m)$. We associate this anomaly with the horizontal and vertical migration of leachate described in profile 2.

\section{Profile 4}

Profile 4 runs NE-SW direction (Fig. 5). From starting point to $150 \mathrm{~m}$, it presents in general high resistivities associated with compacted debris and rubble from old houses. From 150 m, below the surface, to the end of the profile, there is a continuous decrease in resistivity that is associated with the saturated and wet areas of the natural receiving basin where new waste deposits are observed, which are the localized source of production, dilution, vertical migration of leachates and groundwater contamination (< 11.3 - $7.01 \Omega . \mathrm{m}$ ). Between 300 and 340 meters, we note an area that we consider as vertical leachate migration points $(<16.3-11.3 \Omega$.m) causing significant resistivity changes. At depth (6 - $56 \mathrm{~m})$, we note a vast anomaly $(<16.3 \Omega \mathrm{m})$ that we consider related to leachates that dilutes at great depth $>37.3 \mathrm{~m}$ causing possible groundwater contamination $(<8.9-7.01 \Omega . \mathrm{m})$.

\section{Profile 5}

Profile 5 runs in a west-east orientation, at the southern end of the dump (Fig. 6). The electrical resistivity results did not show significant change at the surface level and showed high resistivities associated with the compacted soils and rubble (including asphalt of the street where the profile was executed). This street besides being the southern boundary of the dump is an access to the interior of the Hulene-B neighborhood. Between 130 and $145 \mathrm{~m}$ (> $40 \mathrm{~m}$ depth) extends a resistive zone of low anomalous values, which are interpreted lithologies with influence of migratory leachates $(<8.89-2.24 \Omega . \mathrm{m})$ and possible water contaminated by the vertical movement of leachates $(<0.95-0.403 \Omega . m)$.

\section{Profile 6}

This profile runs at the eastern limit of the dump along S-N direction (Fig. 7), between the dump and Julius Nyerere Avenue (Fig. 9). From the starting point to $200 \mathrm{~m}$ (shallow), there are resistivities with average profile values (> 44.4 - $119 \Omega . \mathrm{m}$ ); these resistivities indicate soils with different levels of compaction and surface moisture that may be associated with various activities south of the dump. The resistivity $>89.1-119 \Omega$.m corresponding to a surficial but thick layer between $160 \mathrm{~m}$ to $200 \mathrm{~m}$ indicates compacted soils at the entrance of the dump. From $8.6 \mathrm{~m}$ depth deep wards, higher resistivity values (> $119 \Omega . \mathrm{m})$ are noted which may be related to the sandstone stratum with different levels of alteration that is typical of the red tip (TPv) formation (Momade et al. 1996; Nogueira et al. 2019). Onwards, in the northern direction, resistivity starts to decrease successively $(<89.1 \Omega \mathrm{m})$ along thick layers with moisture levels that increase until saturated layers $(<14.7 \Omega . \mathrm{m})$. The saturated area occupies a large space and reveals the existence of an E-W groundwater flow parallel to the dune slope where the leachate is located. The groundwater contamination process at this point may be occurring horizontally due to leachate diffusion, causing localized anomalous resistivities (<14.3 $\Omega$.m) close to the groundwater resistivity (< $5.49 \Omega$.m). From $240 \mathrm{~m}$, above the surface, resistivity begins to decrease, generating localized 
anomalous zones in the subsurface, which are associated with vertical leachate migration, points the occurrence of two isolated "hot spots". Between $240 \mathrm{~m}$ and $280 \mathrm{~m}$, below the first "hot spots", there is a tendency for a significant increase in resistivity that may correspond to less saturated layers up to the least conductive stratum $>119 \Omega$.m. The data from this profile show the existence of two mechanisms of possible satured zone and groundwater contamination (14.7 - 3.65 $\Omega . \mathrm{m})$, which are (i) horizontal dilution in the south and center of the profile, (ii) vertical migration and retention of leachate in localized "hot spots".

\subsection{Risk of Groundwater Vulnerability (DRASTIC)}

The values of the DRASTIC index for the whole area are systematized in Table 2 . The assessment of the area covered by profiles $1,3,4$ and 5 showed low vulnerability to groundwater contamination (125-96) as groundwater is at greater depths and the surface lithologies have higher resistivity values, which reduces vertical infiltration of contaminants. However, horizontal migration of leachate at greater depths may affect groundwater at the southern boundary of the area covered by Profile 3 and southwards to the area covered by Profiles 1 and 5. For the area covered by profile 4, the risk becomes even greater as the surface area concentrates the leachate-enriched surface waters and the subsurface substrates exhibited low electrical resistivities (< $16.8 \Omega$.m) demonstrating vertical migration of leachate to greater depths. In the area covered by Profile 2, the relatively steep relief (gentle dune slope) significantly reduces the vertical movement of contaminants, generating a greater horizontal flow of leachate in the surface layers in E-W direction, which may subsequently cause vertical migration of contaminants to groundwater at shallower depths $(<6 \mathrm{~m})$, thus the risk was estimated to be high (156). The area covered by profile 6 , was classified as having a very high vulnerability (165) to groundwater leachate contamination as the groundwater is at a shallower depth $(<3 \mathrm{~m})$ and the surface lithological layers are less resistive $(<59.2$ $\Omega . m)$ and the relief is flat, which demonstrates optimal conditions for leachate infiltration. The overall risk value of vulnerability across the whole area of was estimated to be 127 representing low vulnerability. However, the high values of vulnerability index of the area covered by profiles 2 and 6 , and given their relatively higher altitude, suggest strong groundwater contamination by horizontal dilution of the whole surrounding area of the dump. 
Table 2

Parameter values considered in the DRASTIC Index.

\begin{tabular}{|lllllllll|}
\hline Factor & $\begin{array}{l}\text { Characteristics of the surroundings of } \\
\text { the waste dump }\end{array}$ & P1 & P2 & P3 & P4 & P5 & P6 & Mean \\
\hline D & Depth of groundwater level & 5 & 45 & 5 & 5 & 5 & 45 & 18.3 \\
R & Recharge capacity & 32 & 32 & 32 & 32 & 32 & 32 & 32 \\
A & Sandstone & 21 & 21 & 21 & 21 & 21 & 21 & 21 \\
S & Sandy soils & 9 & 5 & 9 & 9 & 5 & 9 & 7.6 \\
T & $\begin{array}{l}\text { Plan, soft dune and interdune } \\
\text { depression }\end{array}$ & 10 & 5 & 10 & 10 & 5 & 10 & 8.3 \\
I & $\begin{array}{l}\text { Sands } \\
\text { C }\end{array}$ & 30 & 40 & 20 & 40 & 20 & 40 & 31.6 \\
\hline & Hydraulic conductivity & 8 & 8 & 8 & 8 & 8 & 8 & 8 \\
\hline D - Profile & $\mathbf{1 1 5}$ & $\mathbf{1 5 6}$ & $\mathbf{1 0 5}$ & $\mathbf{1 2 5}$ & $\mathbf{9 6}$ & $\mathbf{1 6 5}$ & $\mathbf{1 2 7}$ \\
\hline
\end{tabular}

\subsection{Descriptive statistics of the values of electrical resistivity and DRASTIC index}

The electrical resistivity values of the areas covered by the profiles were projected with the vulnerability index values (Table 3).

Table 3

mean, maximum, minimum, standard deviation of resistivity and DRASTIC index

\begin{tabular}{|llllll|}
\hline ID & MIN & MAX & MEAN & STDV & DRASTIC \\
\hline P1 & 8.64 & 42.36 & 20.78 & 5.72 & 115 \\
\hline P2 & 5.37 & 119.1 & 20.22 & 9.31 & 156 \\
\hline P3 & 10.12 & 50.8 & 31.01 & 7.3 & 105 \\
\hline P4 & 6.98 & 41.19 & 18.1 & 4.64 & 125 \\
\hline P5 & 1.04 & 477.1 & 37.35 & 31.86 & 96 \\
\hline P6 & 3.06 & 207 & 49.2 & 32.78 & 165 \\
\hline P- Profile & & & & \\
\hline
\end{tabular}

In general, the areas covered by profiles 2 and 6 were classified as having a high DRASTIC index. For profile 2 , the average resistivity values were $20.22 \Omega$.m, which demonstrates the predominance of lower resistivities across the entire surface area of the profile, demonstrating that the lithologies are generally 
porous in addition to the shallow groundwater depth. The area covered by profile 6 had an average of $49.2 \Omega$.m, minimum of $3.06 \Omega$.m and maximum of $207 \Omega$.m. The mean resistivity value was relatively higher but presented a much higher standard deviation 32.78, which demonstrates a heterogeneity of the resistivity values, marked by less resistive surface lithological surfaces, i.e. porous lithologies and low depth of groundwater, which may allow a greater migration of leachates and groundwater contamination. These characteristics were determinant in the high DRASTIC risk index. The areas covered by profiles 1, 3 , 4 and 5 presented a low DRASTIC risk and the resistivity values were quite heterogeneous. Thus, the area covered by Profile 1 showed heterogeneities of surface and subsurface anomalies that may be associated with vertical and horizontal migration of contaminants with minimum resistivity values of 5.37 - $8.64 \Omega$.m. The Profile 3 area, showed an average resistivity of $31.01 \Omega . m$, with a minimum value of $10.12 \Omega . \mathrm{m}$ and maximum of $50.8 \Omega \mathrm{m}$. These data demonstrate the predominance of high resistivity values, which is translated by the reduced predominance of resistive surfaces that are interpreted as less permeable substrates. The minimum resistivity at great depth $10.12 \Omega$.m may be indicating the existence of a saturated area or the localized influence of the horizontal migration of contaminants described in profile 2. The area of profile 4, showed an average resistivity of $18.1 \Omega$.m, a minimum of 6.98 and a maximum of $41.89 \Omega . \mathrm{m}$, which demonstrates the strong predominance of conducting surfaces and porous lithology, which are relevant factors in leachate migration and groundwater contamination, which can be justified by the high value of DRASTIC risk. The area covered by profile 5, presented an average resistivity of $37.35 \Omega . \mathrm{m}$ and minimum of $1.04 \Omega . \mathrm{m}$ and maximum of $477.1 \Omega . \mathrm{m}$. The low DRASTIC values in the areas of profiles 1, 3 and 5 resulted from the combination of two factors (i) the high resistivities prevailing in the surface lithologies that are generally impermeable, which greatly reduces the risk of vertical migration of leachate to deep layers, (ii) the greater depth at which the resistivities interpreted as groundwater are located. For profile area 4, only the groundwater depth factor was crucial for the low DRASTIC risk because the superficial layers are less resistive and therefore permeable.

In general, the statistical data showed that the zones whose profiles presented a high average resistivity, the DRASTIC risk was lower (Profile 3 and 5) (Fig. 8). Exceptionally, the area of profile 6 showed a very high DRASTIC risk with relatively high average resistivity values than (1 and 3 ) due to its high standard deviation and to the predominance of resistivities between $<14.71 \Omega . \mathrm{m}$ and $3.65 \Omega . \mathrm{m}$ in a large strip of surface that we associate to migration points of leachate to the underground waters that are located at low depth than in all profiles. However, in the areas of profiles 1 and 4, despite the lower mean resistivity value $20.4-18.1 \Omega . m$, the great depth of groundwater determined the low DRASTIC risk.

\section{Discussion}

The resistivity data presented by the area covered by profiles $1,2,4$ and 6 , with a predominance of surface and groundwater resistivity anomalies, are described in many studies as revealing leachate migration(Parvin and Tareq, 2021) and groundwater contamination(El Mouine et al. 2021),mainly in areas surrounding non-isolated dumps where leachate can freely circulate through the adjacent lithologies and subsequently affect vadose zone and the groundwater (Wysocka et al.2017). Surface circulation and leachate infiltration is well evidenced in profiles 2 and 4 by surface and subsurface resistive anomalies, which are described as indicative of contamination(Netto et al. 2021). The typology 
of the soils (sandy and non-compacted) covering all profiles with strong concentration of resistive values and high DRASTIC index are described as optimal for leachate infiltration at great depths (Wong et al. 2017; Chetri et al. 2021). The zone covered by profile 6, besides showing an extensive layer of low

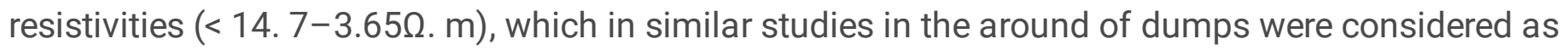
saturated zone and groundwater contaminated by leachates(Brahmi et al. 2021;Adamo et al. 2020), shows also, to the north, two localized points of resistive anomalies, which are called "hot spots" (Ololade et al. 2019;Marques et al. 2021) resulting from vertical migration and localized accumulation of contaminants (Feng et al. 2021; Marques et al. 2021), or may be associated with the confined aquifer system that has been described in this zone as quite vulnerable to contamination given its proximity to the surface and the sandy characteristics of the vadose zone(Cendón et al. 2020). In turn, the resistivity data of profile 3 and 5 characterized by high resistivities, being described as low permeability of contaminants(Gemail et al.2017), because in areas surrounding waste dumps they may be revealing less permeable compacted surfaces (Udosen 2021). Our profile 3 is located far from the waste dump (>350 $\mathrm{m}$ ), which reveals that contaminants may not be reaching this range. Morita et al. (2021) and Oum et al. (2021)demonstrated that the increase in resistivity moving away from the dumpsites shows a significant decrease in contamination, due to the attenuating role of soils and groundwater. The location of the groundwater at great depths in the area covered by profiles $1,3,4$ and 5 has been described in similar studies as a determinant in the low risk of contamination(George 2021), which partly explains the low DRASTIC risk in these areas.Paul et al. (2021) and Boumaiza et al. (2021)mentioned that the depth of groundwater and the characteristics of the infiltration zone are the most important factors determining the DRASTIC risk.Shah et al. (2021),Nasri et al. (2021) and Gemail et al. (2017)integrated electrical conductivity and DRASTIC data and concluded that the areas of highest DRASTIC index around the dumps generally exhibit high electrical conductivity associated with the migration of contamination through adjacent lithologies that may subsequently reach groundwater. The high DRASTIC vulnerability risk of the area covered by profiles 2 and 6 , which in topographic terms are in the high and transitional zone, may constitute evidence of contamination by horizontal groundwater flow. The spatial projection of the DRASTIC Vulnerability Index in the surrounding of the Hulene - B dump was shown to be high to the east and north of the dump (with high and transient relief) and low to the south and west of the dump (low elevation, except for the southern area which is transient) (Fig. 9).However,Blarasin et al. (2021)and Tan et al. (2020)have reported that contamination of the upper levels of the water table leads to the dispersion of contaminants to large areas.

\section{Conclusions}

In this study, the combination of electrical resistivity models and the DRASTIC method proved effective to describe the hydrogeological particularities, estimate in detail the groundwater vulnerability and identify areas of possible leachate contamination in the surroundings of the Hulene - B dump. Thus, the areas covered by profiles 1, 2, 4, and 6 showed strong indications of possible groundwater and surface water contamination by leachate, because the low resistivity values presented in several extensions of the profiles are revealing of surfaces with possible migration or installation of contaminants, besides being 
typical of permeable surfaces, which is a factor to consider in the vertical migration of leachate. Thus, in these areas, the DRASTIC index was very high for the area covered by profiles 2 and $6(156-165)$ given the proximity of groundwater to the contaminating surface and the surrounding area consisting of very conductive materials (sandy soils), while for profiles 1 and 4, despite presenting permeable materials at the surface (low resistivities), groundwater was interpreted at a greater depth $(>40 \mathrm{~m})$ and the DRASTIC risk index was lower (115 - 125). In profiles 5 the index was very low (96) due to the strong resistivity of the surface layers and the high depth at which groundwater was detected $(>40 \mathrm{~m})$. The area of profile 3 further north of the dump also had a low index (105) due to its distance from the contamination (dump) and the strong resistivity of the lithological layers, indicating low permeability, in addition to the great depth $(>40 \mathrm{~m})$ at which the anomalies interpreted as groundwater were detected.

The overall value of the DRASTIC index for the surrounding area was estimated at 127 which represents a low overall vulnerability. However, the high values of vulnerability index of the area covered by profiles 2 and 6 and given their relatively higher altitude, suggest strong groundwater contamination by horizontal dilution of the whole surrounding area of the dump.

The results suggest the need for further studies with quantitative methods to validate the possible contamination in areas of suspected contaminant migration into groundwater. The results of this study recommend:

- To assess contamination monitoring thru installation of piezometers in the anomalous areas (groundwater) that could help understand the pattern of aquifer dynamics and temporal levels of contamination.

- An inventory of all the wells around the dump and temporal chemical quantification of the water could be done to understand the periods of high groundwater contamination and design appropriate methods to minimize the risks for the local.

\section{Declarations}

Ethical Approval: Authors state no potential conflicts of interest, and that research did not involve Human Participants and/or Animals.

Consent to Participate: All authors agreed to participate.

Consent to Publish: All authors consent to publish.

Author Contributions: Conceptualization, B.B. and F.R.; methodology, B.B.; software, B.B.; validation, B.B., C.C. and F.R.; formal analysis, F.R.; investigation, B.B.; resources, B.B.; data curation, B.B.; writing-original draft preparation, B.B.; writing-review and editing, B.B. and F.R.; visualization, B.B.; supervision, F.R. and C.C.; project administration, F.R.; funding acquisition, B.B and F.R.. All authors have read and agreed to the published version of the manuscript. 
Funding: This work was partially supported by GeoBioTec (UIDB/04035/2020) Research Center, funded by FEDER funds through the Operational Program Competitiveness Factors COMPETE and by National funds through FCT. First author acknowledges grants from the Portuguese Institute Camões and FNI (Investigation National Fund - Mozambique).

Conflicts of Interest: The authors declare no conflict of interest.

Availability of data and materials: Not applicable.

\section{References}

1. Adamo N, Al-Ansari N, Sissakian V, Laue J, Knutsson, S (2020) Geophysical Methods and their Applications in Dam Safety Monitoring. Journal of Earth Sciences and Geotechnical Engineering, 11(1), 291-345. https://doi.org/10.47260/jesge/1118

2. Afonso R, (1978) A geologia de Moçambique - notícia explicativa da carta geológica de Moçambique, 1:2000000

3. Akhtar J, Sana A, Mohammed S, Gajendran T, Parmeswari C (2021) Evaluating the groundwater potential of Wadi Al - Jizi , Sultanate of Oman, by integrating remote sensing and GIS techniques. Environmental Science and Pollution Research. https://doi.org/10.1007/s11356-021-17848-x

4. Aller L, Bennett T, Lehr JH, Petty RJ, Hackett G (1987) DRASTIC: A Standardized Method for Evaluating Ground Water Pollution Potential Using Hydrogeologic Settings. Retrieved from NWWA/EPA-600/2-87-035

5. Anshumala K, ShuklaJ P, Patel S S, Singh A (2021) Assessment of Groundwater Vulnerability Zone in Mandideep Industrial Area using DRASTIC Model. Journal of the Geological Society of India, 97, 1080-1086. https://doi.org/10.1007/s12594-021-1823-y

6. Arowoogun K I, Osinowo 00 (2021) 3D resistivity model of 1D vertical electrical sounding (VES) data for groundwater potential and aquifer protective capacity assessment: a case study. Modeling Earth Systems and Environment. https://doi.org/10.1007/s40808-021-01254-w

7. Bernardo B, Candeias $C$, Rocha F (2021) Characterisation of the dynamics of leachate contamination plumes in the surrounding of the Hulene-B waste dump, Maputo, Mozambique. Retrieved from www.preprints.org

8. Bernardo B, Candeias C, Rocha F (2022) Application of Geophysics in geo-environmental diagnosis on the surroundings of the Hulene-B waste dump, Maputo, Mozambique. Journal of African Earth Sciences, 185, 104415. https://doi.org/10.1016/j.jafrearsci.2021.104415

9. Blarasin M, Matiatos I, Cabrera A, Lutri V, Giacobone D, Quinodoz FB (2021) Journal of South American Earth Sciences Characterization of groundwater dynamics and contamination in an unconfined aquifer using isotope techniques to evaluate domestic supply in an urban area. Journal of South American Earth Sciences, 110, 103360. https://doi.org/10.1016/j.jsames.2021.103360 
10. Boufekane A, Yahiaoui S, Meddi H, Meddi M, Busico G (2021) Modified DRASTIC index model for groundwater vulnerability mapping using geostatistic methods and GIS in the Mitidja plain area (Algeria). Environmental Forensics, 1-18. https://doi.org/10.1080/15275922.2021.1913674

11. Boumaiza L, Walter J, Chesnaux R, Brindha K, Elango L (2021) An operational methodology for determining relevant DRASTIC factors and their relative weights in the assessment of aquifer vulnerability to contamination. Environmental Earth Sciences, 80, 1-19. https://doi.org/10.1007/s12665-021-09575-w

12. Brahmi S, Baali F, Hadji R, Brahmi S, Hamad A, Rahal O et al (2021) Assessment of groundwater and soil pollution by leachate using electrical resistivity and induced polarization imaging survey, case of Tebessa municipal landfill, NE Algeria. Arabian Journal of Geosciences, 14. https://doi.org/10.1007/s12517-021-06571-z

13. Cendón DI, Haldorsen S, Chen J, Hankin S, Nogueira GEH, Momade F et al(2020) Hydrogeochemical aquifer characterization and its implication for groundwater development in the Maputo district, Mozambique. Quaternary International, 547, 113-126. https://doi.org/10.1016/j.quaint.2019.06.024

14. Chetri JK, Reddy K R (2021) Advancements in Municipal Solid Waste Landfill Cover System: A Review. Journal of the Indian Institute of Science, 101(4), 557-588. https://doi.org/10.1007/s41745021-00229-1

15. Dhakate R, Mogali NJ, Modi D (2021) Characterization of proposed waste disposal site of granite quarry pits near Hyderabad using hydro-geophysical and groundwater modeling studies. Environmental Earth Sciences, 80, 1-20. https://doi.org/10.1007/s12665-021-09821-1

16. El Mouine Y, El Hamdi A, Morarech M, Kacimi I, Touzani M, Mohsine I, et al (2021). Article landfill pollution plume survey in the moroccan tadla using spontaneous potential. Water (Switzerland), 13, 1-11. https://doi.org/10.3390/w13070910

17. Feng SJ, Wu SJ, Fu WD, Zheng, QT, Zhang XL (2021) Slope stability analysis of a landfill subjected to leachate recirculation and aeration considering bio-hydro coupled processes. Geoenvironmental Disasters, 8(1). https://doi.org/10.1186/s40677-021-00201-2

18. Ferrão DA (2006) Evaluation of removal and disposal of solid waste in Maputo City, Mozambique. Master's thesis, University of Cape Town. Cape Town: South Africa.

19. Gemail KS, Alfy MEl, Ghoneim MF, Shishtawy A M, El-Bary MA (2017) Comparison of DRASTIC and DC resistivity modeling for assessing aquifer vulnerability in the central Nile Delta, Egypt. Environmental Earth Sciences, 76, 1-17. https://doi.org/10.1007/s12665-017-6688-4

20. George NJ(2021) Geo-electrically and hydrogeologically derived vulnerability assessments of aquifer resources in the hinterland of parts of Akwa Ibom State, Nigeria. Solid Earth Sciences, 6, 70-79. https://doi.org/10.1016/j.sesci.2021.04.002

21. Geotomo (2010) RES2DINV ver. 3.59 - Rapid 2-D Resistivity \& IP inversion using the least-squares method Wenner $(a, \beta, \gamma)$, dipole-dipole, inline pole-pole, pole- dipole, equatorial dipole-dipole, offset pole-dipole, Wenner-Schlumberger, gradient and non-conventional arrays. 1-148. 
22. Ghosh R, Sutradhar S, Mondal P, Das N (2021) Application of DRASTIC model for assessing groundwater vulnerability: a study on Birbhum district, West Bengal, India. Modeling Earth Systems and Environment, 7, 1225-1239. https://doi.org/10.1007/s40808-020-01047-7

23. González-Arqueros, ML, Domínguez-Vázquez G, Alfaro-Cuevas-villanueva R, Israde-Alcántaral, Buenrostro-Delgado $O$ (2021) Hazardous solid waste confined in closed dump of morelia: An urgent environmental liability to attend in developing countries. Sustainability (Switzerland), 13, 1-10. https://doi.org/10.3390/su13052557

24. INAM[Mozambique National Meteorological Institute] (2020) Synthesis of temperature and precipitation data 1987-2019, Retrieved from adapted by the author based on data provided by the Maputo meteorological station.

25. Kayode JS, Arifin MH, NawawiM (2019) Characterization of a Proposed Quarry Site using MultiElectrode Electrical Resistivity Tomography. Sains Malaysiana, 48(5), 945-963. https://doi.org/10.17576/jsm-2019-4805-03

26. Koda E, Tkaczyk A, Lech M, Osiński P (2017) Application of electrical resistivity data sets for the evaluation of the pollution concentration level within landfill subsoil. Applied Sciences (Switzerland), 7. https://doi.org/10.3390/app7030262

27. Lau AMP, FerreiraFJF, Stevanato R, da Rosa Filho EF (2019). Geophysical and physicochemical investigations of an area contaminated by tannery waste: a case study from southern Brazil. Environmental Earth Sciences, 78, 1-16. https://doi.org/10.1007/s12665-019-8536-1

28. Liu Y, Yang L, Chun Y, Yang J, Wang C (2021). VFS-based OFSP model for groundwater pollution study of domestic waste landfill. Environmental Science and Pollution Research, 28, 30783-30806. https://doi.org/10.1007/s11356-021-12521-9

29. Marques T, Matias M S, da Silva, EF, Durães N,Patinha C (2021) Temporal and spatial groundwater contamination assessment using geophysical and hydrochemical methods: The industrial chemical complex of estarreja (portugal) case study. Applied Sciences (Switzerland), 11. https://doi.org/10.3390/app11156732

30. Mepaiyeda S, Madi K, Gwavava O, Baiyegunhi C (2020) Heliyon Geological and geophysical assessment of groundwater contamination at the Roundhill land fi II site , Berlin , Eastern Cape , South Africa. Heliyon, 6, e04249. https://doi.org/10.1016/j.heliyon.2020.e04249

31. Momade FJ, Ferrara M, Oliveira JT (1996) Notícia explicativa da carta geológica 2532 Maputo (Escala 1:50 000). Maputo.

32. Morita AKM, Ibelli-Bianco C, Anache JAA, CoutinhoJV, Pelinson NS, Nobrega J et al (2021) Pollution threat to water and soil quality by dumpsites and non-sanitary landfills in Brazil: A review. Waste Management, 131, 163-176. https://doi.org/10.1016/j.wasman.2021.06.004

33. Muchangos A dos(1999) Paisagens e Regiões Naturais 1999 5. 5-163.

34. Muchimbane ABD (2010) Estudo dos indicadores da contaminação das aguas subterrâneas por sistemas de saneamento in Situ - Distrito Urbano 4, Cidade de Maputo, Moçambique. Dissertação de Mestrado. https://doi.10.11606/D.44.2010.tde-06052010-153107 
35. Nasri, G., Hajji, S., Aydi, W., Boughariou, E., Allouche, N., \& Bouri, S. (2021). Water vulnerability of coastal aquifers using AHP and parametric models: methodological overview and a case study assessment. Arabian Journal of Geosciences, 14. https://doi.org/10.1007/s12517-020-06390-8

36. NettoLG, Filho WM, Moreira CA, di Donato FT, Helene L PI (2021) Delineation of necroleachate pathways using electrical resistivity tomography (ERT): Case study on a cemetery in Brazil. Environmental Challenges, 5, 100344. https://doi.org/10.1016/j.envc.2021.100344

37. NogueiraG, Stigter TY, Zhou Y, Mussa F, Juizo D (2019) Understanding groundwater salinization mechanisms to secure freshwater resources in the water-scarce city of Maputo, Mozambique. Science of the Total Environment, 661, 723-736. https://doi.org/10.1016/j.scitotenv.2018.12.343

38. Ololade OO, Mavimbela S, Oke SA, Makhadi R (2019) Impact of leachate from northern landfill site in Bloemfontein on water and soil quality: Implications for water and food security. Sustainability (Switzerland), 11. https://doi.org/10.3390/su11154238

39. Oum TM, Mohsine I, Ouardi J, Kacimi I, Morarech M, Mahrad B El (2021) Mapping the Pollution Plume Using the Self-Potential.

40. PalalaneJ, Segala I, amp O (2008) Urbanização e desenvolvimento municipal em Moçambique: gestão de resíduos sólidos.

41. ParvinF, Tareq SM (2021) Impact of landfill leachate contamination on surface and groundwater of Bangladesh: a systematic review and possible public health risks assessment. Applied Water Science, 11, 1-17. https://doi.org/10.1007/s13201-021-01431-3

42. Paul S, Surabhi C (2021) An investigation of groundwater vulnerability in the North 24 parganas district using DRASTIC and hybrid-DRASTIC models: A case study. Environmental Advances, 5, 100093. https://doi.org/10.1016/j.envadv.2021.100093

43. Persaud E, Levison J (2021) Impacts of changing watershed conditions in the assessment of future groundwater contamination risk. Journal of Hydrology, 603, 127142. https://doi.org/10.1016/j.jhydrol.2021.127142

44. Rathi BS, Kumar PS, Vo DVN (2021)Critical review on hazardous pollutants in water environment: Occurrence, monitoring, fate, removal technologies and risk assessment. Science of the Total Environment, 797, 149134. https://doi.org/10.1016/j.scitotenv.2021.149134

45. Saranya T, Saravanan S (2021) A comparative analysis on groundwater vulnerability models-fuzzy DRASTIC and fuzzy DRASTIC-L. Environmental Science and Pollution Research. https://doi.org/10.1007/s11356-021-16195-1

46. Sarmento L, Tokai A, Hanashima A (2015) Analyzing the structure of barriers to municipal solid waste management policy planning in Maputo city , Mozambique. Environmental Development, 16, 76-89. https://doi.org/10.1016/j.envdev.2015.07.002

47. Serra C (2012) Da problemática Ambiental à mudança: rumo à um mundo melhor. Retrieved from ISBN\%0A9789896700300

48. Shah SHI, Yan J, Ullah I, Aslam B, Tariq A, Zhang L, Mumtaz F (2021) Classification of aquifer vulnerability by using the drastic index and geo-electrical techniques. Water (Switzerland), 13. 
https://doi.org/10.3390/w13162144

49. Sresto MA, Siddika S, Haque MN, Saroar M (2021) Groundwater vulnerability assessment in Khulna district of Bangladesh by integrating fuzzy algorithm and DRASTIC (DRASTIC-L) model. Modeling Earth Systems and Environment. https://doi.org/10.1007/s40808-021-01270-w

50. Tan M, Wang K, Xu Z, Li H, Qu J (2020) Study on Heavy Metal Contamination in High Water Table Coal Mining Subsidence Ponds That Use Di ff erent Resource Reutilization Methods. https://doi.org/10.3390/w12123348

51. Udosen NI (2021) Geo-electrical modeling of leachate contamination at a major waste disposal site in south-eastern Nigeria. Modeling Earth Systems and Environment, (0123456789).

https://doi.org/10.1007/s40808-021-01120-9

52. VOA (Voice of America News) (2018) Desabamento de lixeira deixa 17 mortos em Maputo.

53. Voudouris K (2021) Groundwater Quality and Groundwater Vulnerability Assessment. 8-9.

54. Wong JTF, Chen Z, ChenX, Ng C WW, Wong MH (2017) Soil-water retention behavior of compacted biochar-amended clay: a novel landfill final cover material. Journal of Soils and Sediments, 17, 590598. https://doi.org/10.1007/s11368-016-1401-x

55. Wysocka ME, Zabielska-Adamska K (2017) Impact of protective barriers on groundwater quality. 10th International Conference on Environmental Engineering, ICEE 2017.

https://doi.org/10.3846/enviro.2017.063

\section{Figures}

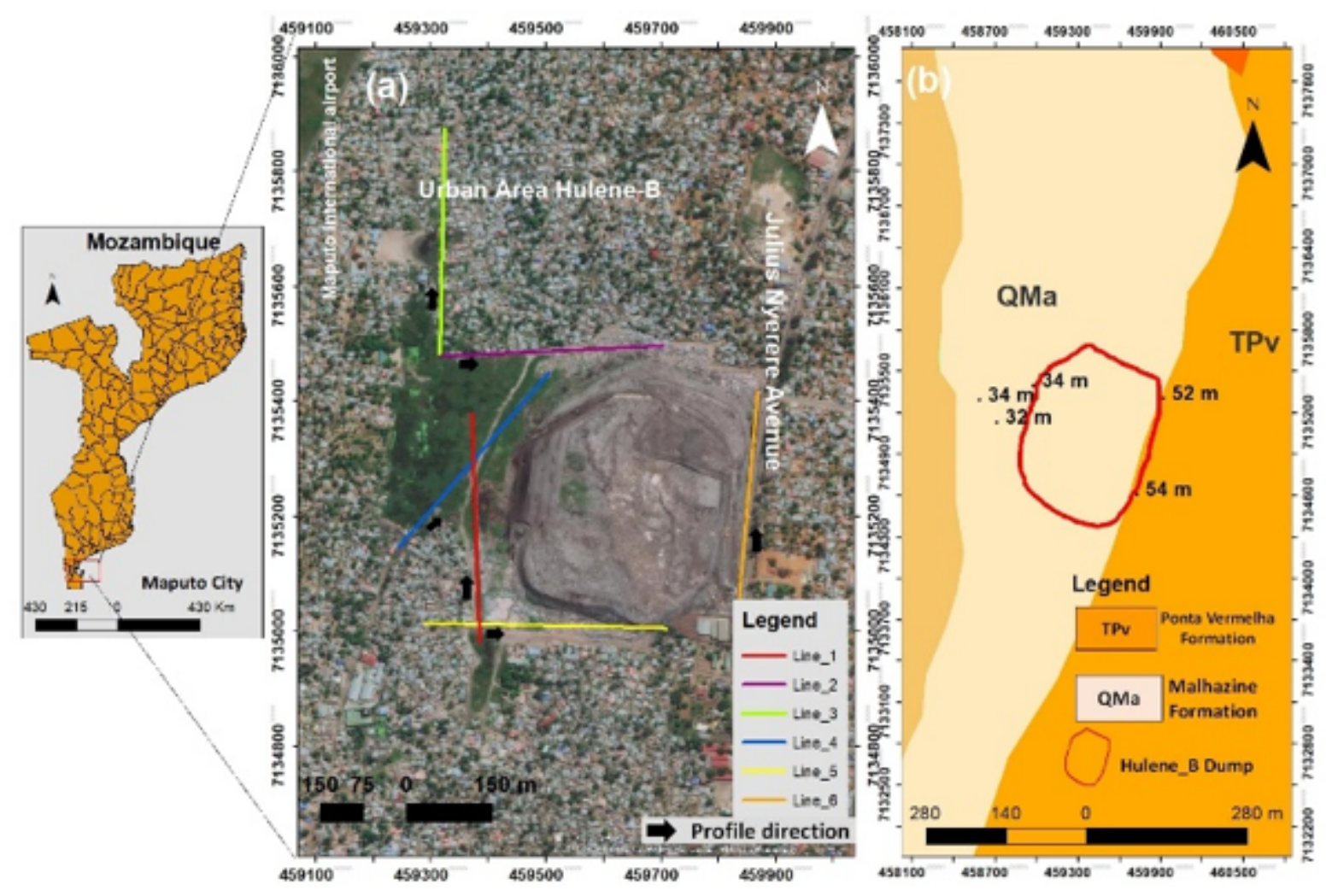


Figure 1

(a) Location, Profiles, (b) Geology, Topography. Adapt. Bernardo et al. (2021) and Momade et al. (1996).

S 1

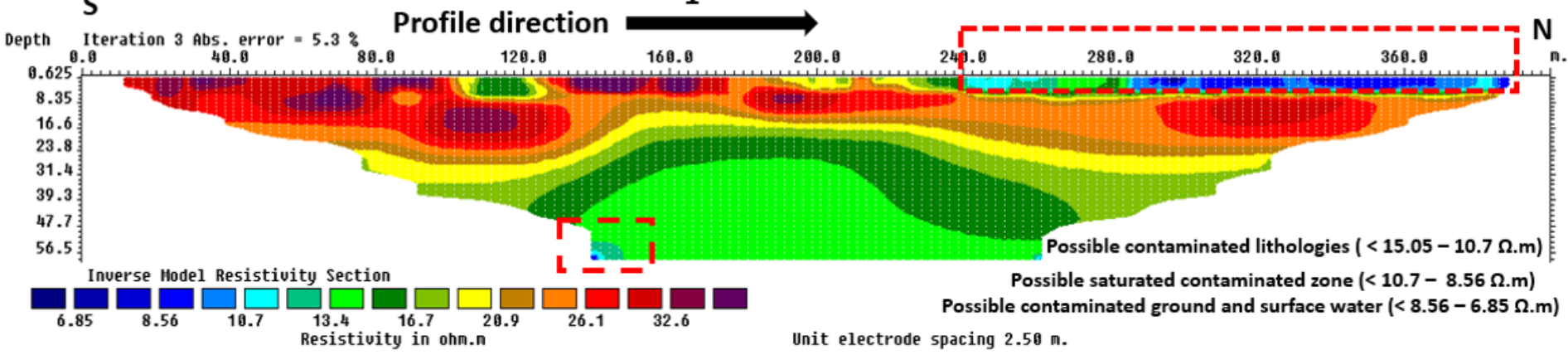

Figure 2

Electrical resistivity model of profile 1. Adapt. Bernardo et al. (2021)

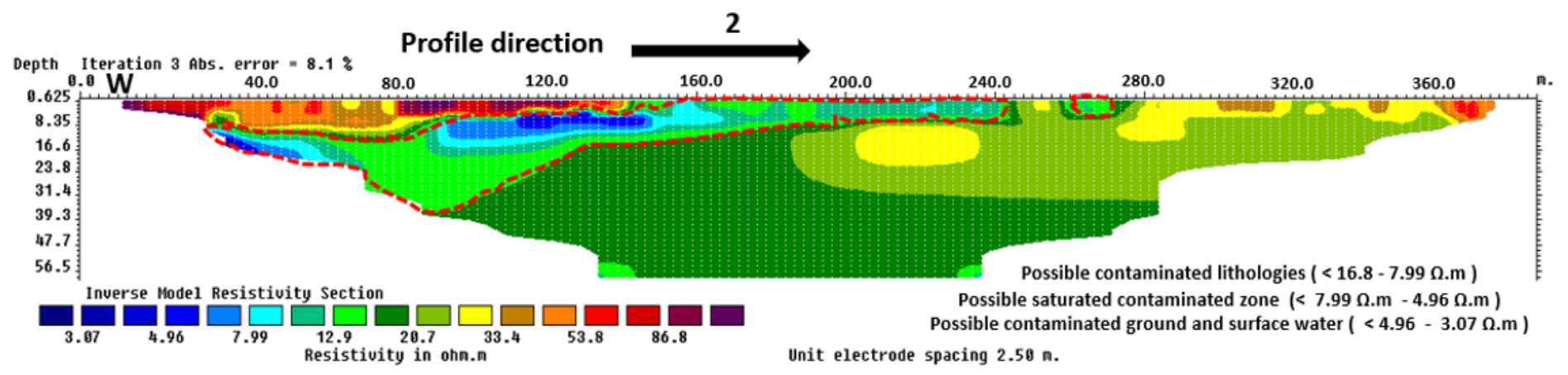

Figure 3

Electrical resistivity model of profile 2. Adapt. Bernardo et al. (2021)

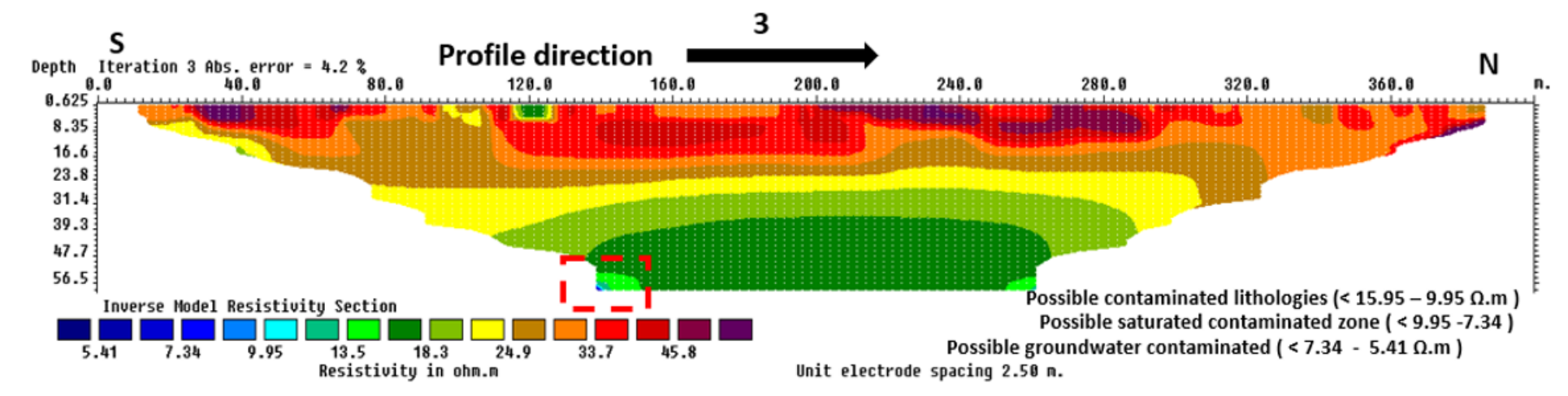


Figure 4

Electrical resistivity model of profile 3. Adapt. Bernardo et al. (2021)

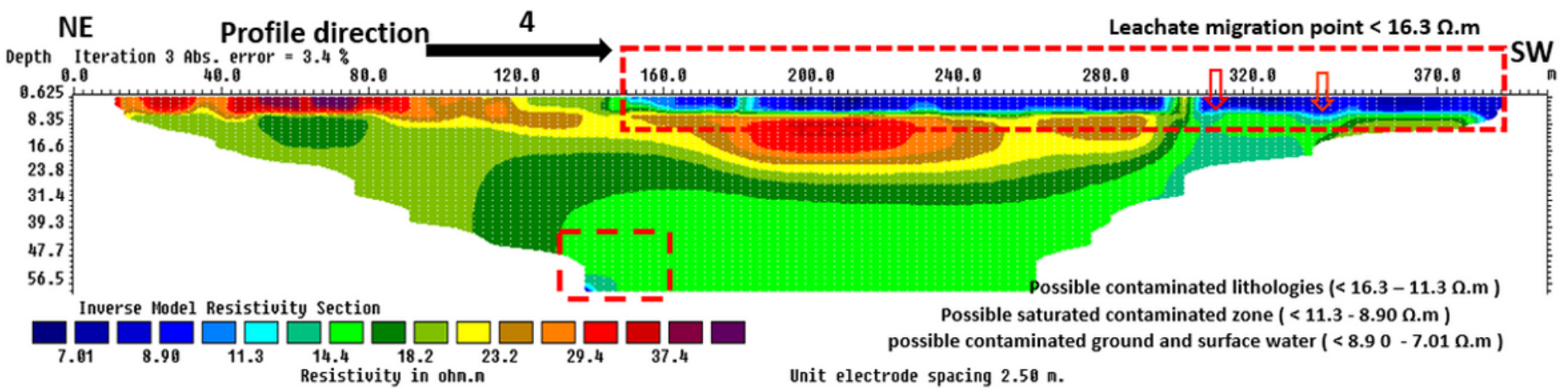

\section{Figure 5}

Electrical resistivity model of profile 3. Adapt. Bernardo et al. (2021)

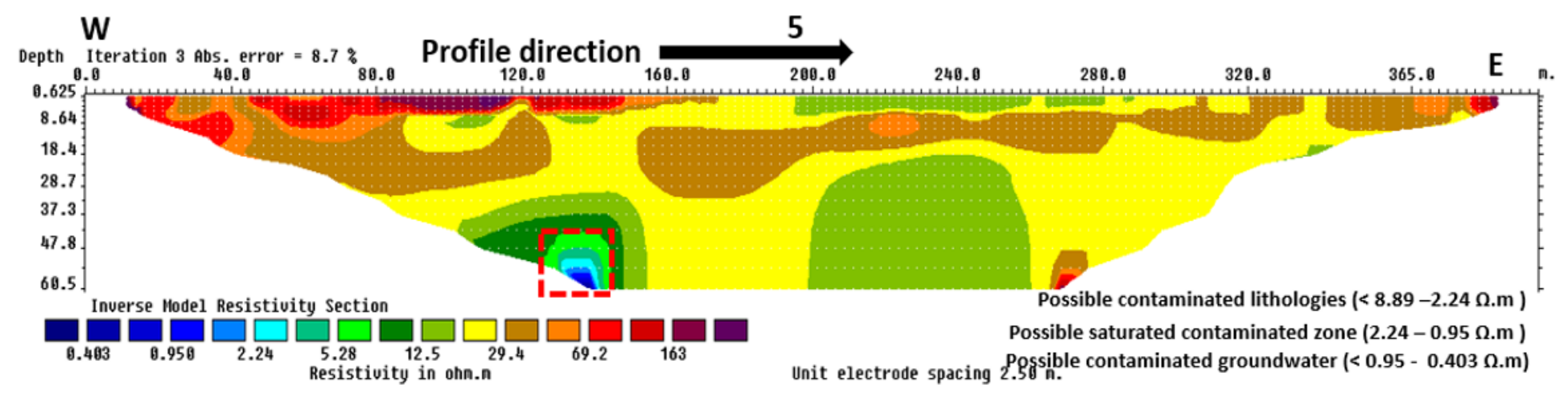

\section{Figure 6}

Electrical resistivity model of profile 5.

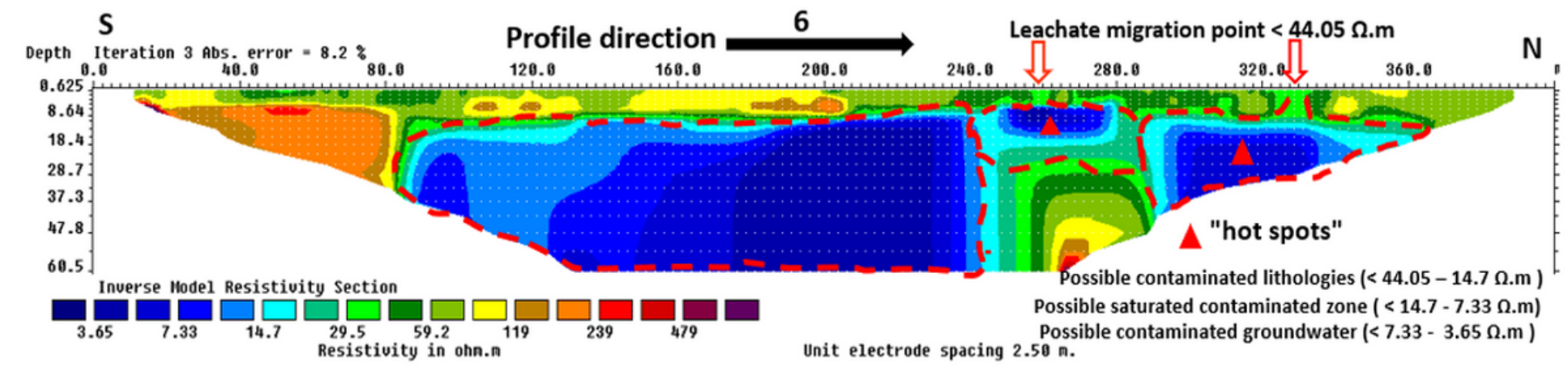


Figure 7

Electrical resistivity profile 6

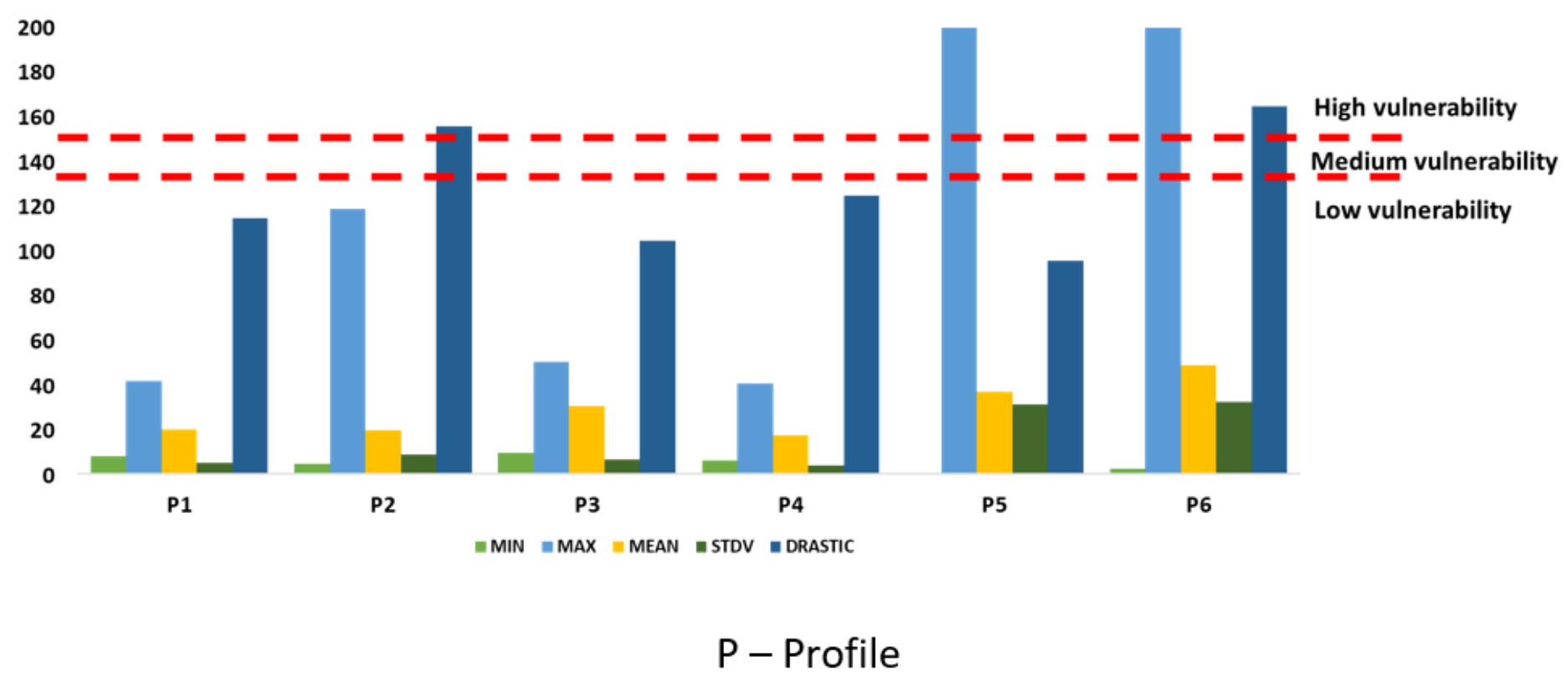

Figure 8

Electrical resistivity values (minimum, maximum, mean, standard deviation) and DRASTIC Index 


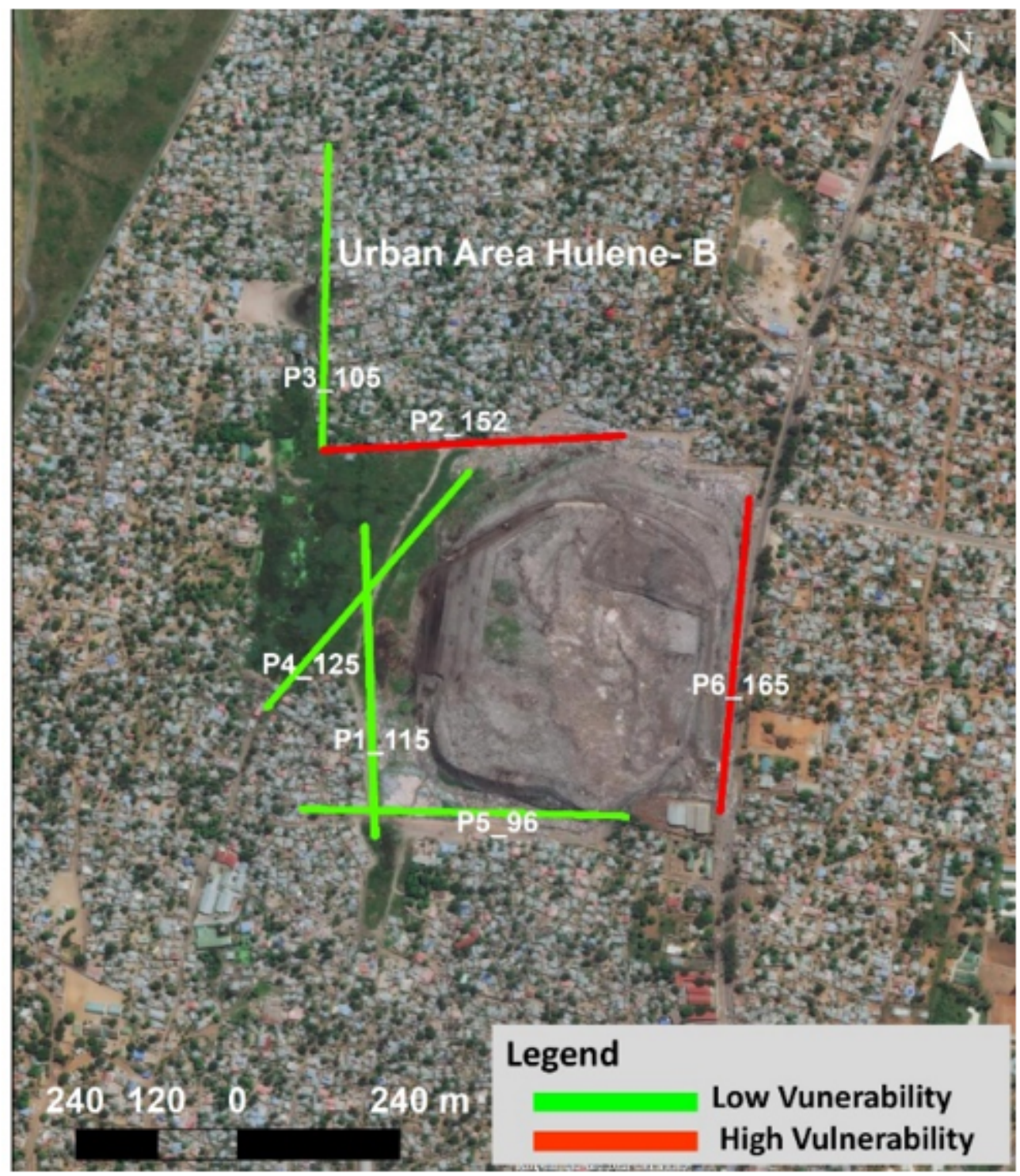

\section{Figure 9}

Spatial projection of the DRASTIC Vulnerability Index in the surrounding of the Hulene - B Waste dump. 